\title{
Protein Secretion
}

National Cancer Institute

\section{Source}

National Cancer Institute. Protein Secretion. NCI Thesaurus. Code C18971.

Vectorial transport of proteins across a cell membrane to the extracellular environment. 